\title{
MERCURY IN SOILS AND SEDIMENTS FROM GOLD MINING LIABILITIES IN SOUTHERN AMAZONIA
}

\author{
Julio Cesar Wasserman* \\ Instituto de Geociências, Universidade Federal Fluminense, Av. Litorânea, s/n, 24210-340 Niterói - RJ, Brasil \\ Reinaldo Calixto Campos \\ Departamento de Química, Pontifícia Universidade Católica do Rio de Janeiro, Rio de Janeiro - RJ, Brasil \\ Sandra de Souza Hacon \\ Escola Nacional de Saúde Pública, Fundação Instituto Oswaldo Cruz, Rio de Janeiro - RJ, Brasil \\ Renato A. Farias \\ Centro de Aqüicultura, Universidade Estadual Paulista, Jaboticabal - SP, Brasil \\ Sandro M. Caires \\ Departamento de Solos e Nutrição de Plantas, Universidade Federal de Viçosa, Viçosa - MG, Brasil
}

Recebido em 8/11/05; aceito em 24/8/06; publicado na web em 26/3/07

\begin{abstract}
The 1980-1990 Amazonian gold rush left an enormous liability that increasingly has been substituted by developing fish aquaculture. This work aimed at the identification of the mercury levels in the environment, associated with fish farms located in the North of Mato Grosso State, Southern Amazon. Sediment and soil samples were analyzed for total organic carbon and total mercury. Results indicate that the chemical characteristics of the sediment largely depend on the management procedures of the fish pond (liming, fish food used and fish population). The soils presented relatively low concentrations when compared with other data from the literature.
\end{abstract}

Keywords: mercury; fish farm; Amazon.

\section{INTRODUCTION}

Due to the drop of the gold prices in the international market, alongside the exhaustion of the more accessible sources, its mining has decreased from 100 tons a year in the eighties, to less than 30 tons a year in the late nineties ${ }^{1}$ in the Amazon Region. If gold yielded large incomes for the gold dealers, only a few miners got rich, while nothing was left for the small land owners other than to attend the wild occupation and destruction of their agricultural areas. One of the most conspicuous scenarios left by gold mining is the craterlike landscape, completely devoided of vegetation where nothing can grow. After 10 years of the "gold rush", the land owners inherited a considerable liability, since mining was carried out with no environmental concern, and now they are confronted with the challenge of recovering the economic use of their lands.

Among the activities that have shown to be suitable for the mined areas, the most successful was aquaculture. In the states of Pará and Mato Grosso there has been a significant increase in the number of aquaculture farms. The last Brazilian census ${ }^{2}$ (year 2000) reports a total of 307 and 378 Artisan fish farms in Pará and Mato Grosso, respectively. In the North of Mato Grosso, Hacon and colleagues $^{3}$ identified 255 areas of fish farming. In these farms, the most cultivated species are Tambaqui (Colossoma macropomum), Tambacú (Colossoma macropomum) and Pacú (Piaractus mesopotamicus), that are very well accepted by the local community and have also been exported and sold in other Brazilian regions.

Although aquaculture has already shown to present very high income for the local communities, the fact that fish farms are mostly being carried out into mercury liabilities ${ }^{3}$ may engender a serious treat to humans ${ }^{4}$. A brief budget of the anthropogenic inputs to the Amazonian environment leads to a worrying picture. The amount

*e-mail: geowass@vm.uff.br of mercury released during the 1980's gold rush is estimated to be greater than two thousand tones ${ }^{5-7}$. Furthermore, this liability is only a small contribution to the amount released by the Spanish and Portuguese, during over 200 years of gold and silver mining during the colonial times in South America ${ }^{8}$. On the other hand, there are now evidences that Amazonian soils should present naturally elevated and widespread concentrations of mercury ${ }^{9-12}$. These naturally elevated concentrations reflect on mercury contents of fishes, which are living in areas distant from any anthropogenic source of the metal ${ }^{13,14}$.

Wasserman et al. ${ }^{1}$ presented a detailed discussion of the sources of mercury in soils of the Amazonian environment in a review of the cycling of this pollutant. Briefly, these authors refute the possibility of geologic origin, since no mercury bearing rock has ever been observed in the region. Nonetheless, they suggest that the sources for mercury in the Amazonian environment are mainly anthropogenic, but, due to the chemical characteristics of some soils (ferralytic soils ${ }^{15}$ ), the element would be retained for longer periods, therefore increasing their concentrations. Once only localized soils have been studied and the concentrations of mercury in the whole Amazonian soils are still barely known, any of the former assumptions can not be taken as definitive.

The present work is part of a larger research program, carried out at the northern region of the Mato Grosso State, in the southern Amazon, that is meant to study the possible pathways by which mercury, if associated to fish farming, may reach humans and thereby constitute a health treat. The work presented in this paper was carried out to provide information on the concentrations and distribution of total mercury in soils and sediments on areas where fish aquaculture has been established. Mercury concentrations in some fish species are also presented. Even though the present work is limited to only two (Alta Floresta and Paranaíta) of the ten counties of the region, it also constitutes a contribution for the 
understanding of the mercury behavior in the soils, sediments and possible transfer processes in fish of the entire Amazon Region.

\section{METHODS}

\section{Sampling sites and collection}

The studied area is presented in Figure 1. Their soils have already been described by Barbosa e Neves ${ }^{16}$, who pointed out the general homogeneity of the pedological units of the region. The most common pedological unit is known as Machado Unity and is constituted of red-yellow podzolic soil with low nutrient loads. Although the soils were originally covered with thick and tall Amazonian forest, the whole region has suffered from intensive deforestation, carried out mainly with forest fires. In many places, carbonized trunks of tall trees can still be observed emerging from very extensive grasslands. Most of the remaining vegetation can be observed in the margin of the rivers, which are constituted of hydromorphous soils and can be flooded for six months during rainy season.

Soil samples were collected from areas that were close to the fish ponds in four farms (Figure 1). As displayed in Table 1, some of the fish farms have been subject to gold mining (farms 2 and 3) while others not. Although farms 1 and 4 were never subject to contamination, indirect sources such as atmospheric deposition can not be discarded ${ }^{17}$. Horizons (as described in Table 1) were sampled with a manual inox drill and each level was placed in plastic bags, that was immediately ice refrigerated for transportation to the UNEMAT laboratory, at the Alta Floresta city, where they were kept in freezer $\left(-20^{\circ} \mathrm{C}\right)$, transported to our laboratories in Rio de Janeiro and then analyzed. Sediment samples were collected from the fish ponds with a box corer (15 $\mathrm{cm}$ depth). Layers of $4 \mathrm{~cm}$ were separated and placed in plastic bags, ice refrigerated and transported to the laboratory where they were kept in freezer $\left(-20{ }^{\circ} \mathrm{C}\right)$ until analysis. Five sediment cores were collected from farms 2, 3 and 4 (Figure 1). Unfortunately, farm 1 sediments were lost during transportation and no results could be presented. Sediment samples from farm 2 were collected from two neighboring ponds that had roughly the same characteristics, but $2 \mathrm{~B}(1.45 \mathrm{~m})$ was shallower than $2 \mathrm{~A}(1.70 \mathrm{~m})$. Sediment sample 3A, which was located in farm 3, was too sandy and a complete core could not be drawn, therefore, only the superficial $(5 \mathrm{~cm})$ sediment was collected. Another sediment core was drawn from a neighboring pond in farm 3 (sample 3B). A brief description of the water column characteristics is presented in Table 2.

Various fish species were collected from the ponds where sediments were collected. A list of the sampled species is presented in Table 3.

\section{Analytical procedures}

The analyses were performed at the PUC and UFF laboratories in Rio de Janeiro. Both sediments and soils were prepared and analyzed the same way: The samples were oven dried at $50{ }^{\circ} \mathrm{C}$ for three days and finely ground in an agate mortar. The moisture content was determined, by weighting the samples before and after drying. Fifty milligrams of soils samples and ten milligrams of sediment sample were weighted for the total organic carbon (TOC)
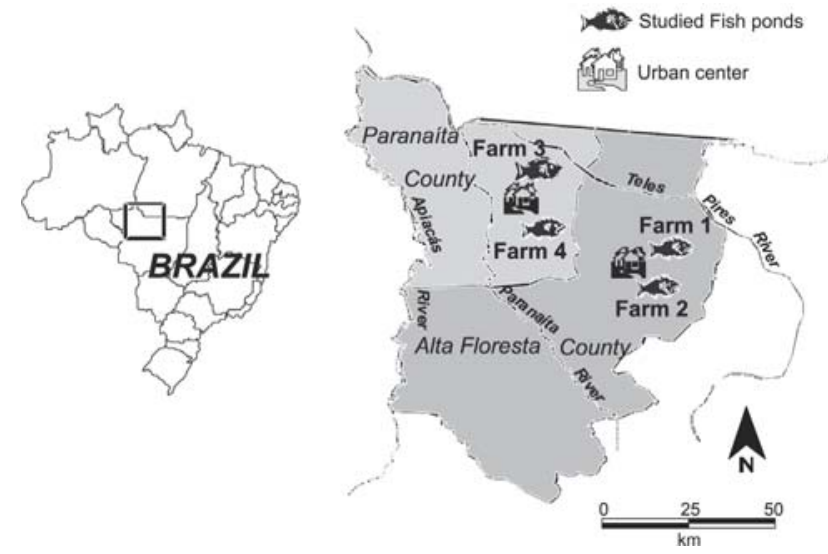

Figure 1. Location of the studied fish farms

Table 1. Description of the soil samples collected in the neighborhood of the fish ponds

\begin{tabular}{|c|c|c|c|c|c|c|}
\hline $\begin{array}{l}\text { Sample } \\
\text { code }\end{array}$ & $\begin{array}{c}\text { Geographic } \\
\text { coordinates (UTM) }\end{array}$ & $\begin{array}{c}\text { Soil } \\
\text { classification }\end{array}$ & Location & $\begin{array}{l}\text { Presence of } \\
\text { gold mining }\end{array}$ & $\begin{array}{c}\text { Type of } \\
\text { vegetation }\end{array}$ & Sampled horizons \\
\hline WPS1 & $\begin{array}{l}\text { X } 603171 \\
\text { Y } 8904876\end{array}$ & Ultisol & $\begin{array}{l}\text { Alta Floresta } \\
\text { Farm } 1\end{array}$ & Never & Grassland & $\begin{array}{l}A_{1}(0-20 \mathrm{~cm}), A_{2}(20-30 \mathrm{~cm}) \\
B_{1}(30-50 \mathrm{~cm}), B_{2}(50-60 \mathrm{~cm}), \\
B_{3}(60-70 \mathrm{~cm})\end{array}$ \\
\hline WPS2 & $\begin{array}{l}\text { X } 603337 \\
\text { Y } 8904913\end{array}$ & Ultisol & $\begin{array}{l}\text { Alta Floresta } \\
\text { Farm } 1\end{array}$ & Never & $\begin{array}{l}\text { Fruit tree } \\
\text { wood }\end{array}$ & $\begin{array}{l}A_{1}(0-20 \mathrm{~cm}), A_{2}(20-30 \mathrm{~cm}), \\
B_{1}(30-40 \mathrm{~cm}), B_{2}(40-60 \mathrm{~cm}), \\
B_{3}(60-80 \mathrm{~cm}), B_{4}(80-100 \mathrm{~cm})\end{array}$ \\
\hline WPS3 & $\begin{array}{l}\text { X } 0603604 \\
\text { Y } 8915192\end{array}$ & $\begin{array}{l}\text { Very leached } \\
\text { Podzolic }\end{array}$ & $\begin{array}{l}\text { Alta Floresta } \\
\text { Farm } 2\end{array}$ & Previous & Grassland & $\begin{array}{l}A_{1}(0-20 \mathrm{~cm}), A_{2}(20-30 \mathrm{~cm}), \\
B_{1}(30-40 \mathrm{~cm}), B_{2}(40-60 \mathrm{~cm}), \\
B_{3}(60-80 \mathrm{~cm})\end{array}$ \\
\hline WPS4 & $\begin{array}{l}\text { X } 0603649 \\
\text { Y } 8915375\end{array}$ & Ultisol & $\begin{array}{l}\text { Paranaita } \\
\text { Farm } 3\end{array}$ & Previous & Forest & $\begin{array}{l}A_{1}(0-20 \mathrm{~cm}), A_{2}(20-30 \mathrm{~cm}) \\
B_{1}(30-40 \mathrm{~cm}), B_{2}(40-60 \mathrm{~cm})\end{array}$ \\
\hline WPS6 & $\begin{array}{l}\text { X } 0561861 \\
\text { Y } 8926179\end{array}$ & Ultilsol & $\begin{array}{l}\text { Paranaita } \\
\text { Farm } 4\end{array}$ & Never & Forest & $\begin{array}{l}A_{1}(0-20 \mathrm{~cm}), A_{2}(20-30 c \mathrm{~cm}), \\
B_{1}(30-40 \mathrm{~cm}), B_{2}(50-60 \mathrm{~cm}), \\
B_{3}(60-70 \mathrm{~cm}), B_{4}(70-80 \mathrm{~cm}), \\
B_{5}(80-90 \mathrm{~cm}), B_{6}(200-220 \mathrm{~cm})\end{array}$ \\
\hline WPS7 & $\begin{array}{l}\text { X } 0561977 \\
\text { Y } 8926468\end{array}$ & $\begin{array}{l}\text { Euthrophic } \\
\text { Podzolic }\end{array}$ & $\begin{array}{l}\text { Paranaita } \\
\text { Farm } 4\end{array}$ & Never & Cocoa wood & $\begin{array}{l}A_{1}(0-20 \mathrm{~cm}), A_{2}(20-30 \mathrm{~cm}), \\
B_{1}(30-40 \mathrm{~cm}), B_{2}(40-50 \mathrm{~cm}), \\
B_{3}(50-60 \mathrm{~cm}), B_{4}(60-80 \mathrm{~cm})\end{array}$ \\
\hline
\end{tabular}


Table 2. Water column characteristics pf the ponds where sediments were collected

\begin{tabular}{|c|c|c|c|c|c|}
\hline & \multicolumn{5}{|c|}{ Fish-farms } \\
\hline & $2 \mathrm{~A}$ & $2 \mathrm{~B}$ & $3 \mathrm{~A}$ & $3 \mathrm{~B}$ & 4 \\
\hline UTM X & 603604 & 603649 & 557814 & 558685 & 561935 \\
\hline UTM Y & 8915192 & 8915375 & 8944647 & 8944791 & 8926243 \\
\hline Age of the pond (years) & 4 & 4 & 12 & 6 & 10 \\
\hline Surface $\left(\mathrm{m}^{2}\right)$ & 2.000 & 1.800 & 70.000 & 10.000 & 15.000 \\
\hline Fish production $\left(\mathrm{kg}\right.$ year $\left.^{-1}\right)$ & 1.000 & 900 & 35.000 & 5.000 & 7.500 \\
\hline Depth $(\mathrm{m})$ & 1.70 & 1.45 & 2.20 & 1.70 & 2.00 \\
\hline $\mathrm{O}_{2}\left(\mathrm{mg} \mathrm{L}^{-1}\right)$ & 3.59 & 4.63 & 1.70 & 4.63 & 0.65 \\
\hline Temperature $\left({ }^{\circ} \mathrm{C}\right)$ & 31.2 & 31.6 & 28.4 & 31.6 & 27.7 \\
\hline $\mathrm{pH}$ & 6.2 & 7.1 & 5.9 & 7.1 & 6.1 \\
\hline Conductivity $(\mu \mathrm{S})$ & 40 & 64 & 27 & 64 & 30 \\
\hline Turbidity (NTU) & 8.6 & 4.0 & 0.2 & 4.0 & 0.7 \\
\hline Alcalinity & 35 & 30 & 25 & 30 & 30 \\
\hline Secchi (m) & 0.75 & 1.40 & 1.55 & 1.40 & 45 \\
\hline Eh $(\mathrm{mV})$ & 58 & 70 & -140 & 70 & -30 \\
\hline
\end{tabular}

Table 3. Fish characteristics and concentrations of mercury in the studied farms

\begin{tabular}{llccc}
\hline Location & species & Trophic level & Weight $(\mathrm{kg})^{*}$ & $\mathrm{Hg}(\mathrm{mg} \mathrm{kg})^{*}$ \\
\hline Farm 2B & Trairão (Hoplias lacerdae) & Carnivorous & 5.5 & 1.30 \\
& Tucunaré (Chichia ocellaris) & Carnivorous & 0.9 & 0.30 \\
& Tambaqui (Colossoma macropomum) & Herbivorous & 1.6 & 0.02 \\
& Tambacú (Colossoma macropomum) & Herbivorous. & 1.9 & 0.02 \\
& Cará (Geophagus brasiliensis) & Herbivorous. & 0.1 & 0.09 \\
Farm 3A & Trairão (Hoplias lacerdae) & Carnivorous. & 5.5 & 1.30 \\
& Tucunaré (Chichia ocellaris) & Carnivorous & 1.1 & 0.30 \\
& Tambaqui (Colossoma macropomum) & Herbivorous. & 1.6 & 0.02 \\
Farm 2A & Tambacú (Colossoma macropomum) & Herbivorous. & 1.8 & 0.03 \\
& Traira (Hoplias malabaricus) & Carnivorous. & 0.2 & 0.31 \\
Farm 4 & Tucunaré (Chichia ocellaris) & Carnivorous & 1.1 & 0.22 \\
& Traira (Hoplias malabaricus) & Carnivorous. & 0.2 & 0.15 \\
& Tucunaré (Chichia ocellaris) & Carnivorous & 1.0 & 0.14 \\
Various Amazonian rivers & Tambaqui (Colossoma macropomum) & Herbivorous. & 1.5 & 0.07 \\
Northern Mato Grosso & Tambacú (Colossoma macropomum) & Herbivorous. & 0.8 & 0.02 \\
& Fishes from over 250 sampling sites, & Carnivorous & $0.01-5.00$ (range) & Herbivorous \\
& including rivers and reservoirs & $0.02-3.50$ (range) & \\
\hline
\end{tabular}

\footnotetext{
*Average values
}

determination. The TOC procedure described in Strickland and Parsons ${ }^{18}$ was originally developed for the analysis of suspended matter, but it was adapted for sediments and soils and has been largely used for this purpose $e^{7,19,20}$. The procedure is based on the chemical (wet) oxidation of the carbon compounds with a sulfuric-chromic acid solution. The chromium excess is titrated with ammonium ferrous sulfate. The results are given on a dry weight basis.

Total mercury determination was carried out in triplicate wet sediment and soil samples, in order to avoid contamination or losses. The procedure described by Malm et al. ${ }^{21}$ applies wet leaching with aqua regia $\left(\mathrm{HCl}+\mathrm{HNO}_{3}, 1: 3\right)$ to one gram of wet sediment. The leaching was carried out for one hour at $50{ }^{\circ} \mathrm{C}$ in erlenmeyer glass flasks, equipped with special condensers (cold finger). Samples were cooled down to the ambient temperature transferred to $50 \mathrm{~mL}$ disposable centrifuge plastic tubes made up to $30 \mathrm{~mL}$ and centrifuged at $4000 \mathrm{rpm}$ for $15 \mathrm{~min}$. An aliquot of the supernatant was separated for immediate analysis by cold vapor atomic absorption spectrometry (CVAAS). Stannous chloride was used as reducing agent. The results were calculated on a dry weight basis, correcting the results for moisture. A detection limit $(3 \times \mathrm{SD})$ of 30 ng $\mathrm{g}^{-1}$ was estimated from ten blank analyses. Quality assurance was attained by the repeated parallel analysis of soil and sediment certified reference materials (Table 4). Results were always within the $\pm 10 \%$ range in relation to the certified values.

The total mercury determination in fish was performed by cold vapor atomic absorption spectrometry, after acid digestion (1:1 sulfuric+nitric acids, in the presence of $0.1 \%$ vanadium pentoxide) of wet samples, followed by potassium permanganate oxidation,

Table 4. Results of quality assurance/quality control of the mercury analyses

\begin{tabular}{lcc}
\hline & \multicolumn{2}{c}{${\mathrm{Hg}\left(\mathrm{ng} \mathrm{g}^{-1}\right)}$} \\
& Obtained & Certified \\
\hline BCR 320, river sediment & $1,024 \pm 6$ & $1,030 \pm 160$ \\
NRCC - MESS-3, & $87 \pm 4$ & $91 \pm 9$ \\
marine sediment & & \\
NRCC - TORT-1, & $280 \pm 20$ & $330 \pm 60$ \\
Lobster hepatopancreas & & \\
\hline
\end{tabular}


as described in Campos and Curtius ${ }^{22}$. Analytical quality was assured by a strict blank control (detection limits $=0,007 \mathrm{mg} \mathrm{kg}^{-1}$ ), duplicate analysis and the analysis of adequate certified reference materials (Table 4).

\section{RESULTS AND DISCUSSION}

\section{Sediments and fish}

Figures 2 and 3 show the behaviour of TOC and mercury in the sediment profiles from the sampled ponds. In order to understand the behaviour of these parameters, it is necessary to consider that in fish ponds, chemical and physical managements are necessary to reach or keep the conditions as suitable as possible for a faster fish growth. Therefore, pond liming is frequent, once organic matter decay makes the already low water $\mathrm{pH}$ even more acidic. The intensive introduction of fish food and the overpopulation of the ponds are factors that also affect their characteristics. These factors should respond for the observed TOC profiles, as shown in Figure 2. According to its owner little management was carried out in farm 2, fish population was reduced and growth was consequently slow. Accordingly, TOC concentrations in these ponds where found to be the lowest. On the other hand, in farm 3, due to attempts for increasing productivity, significantly more fish food was introduced into the system and the ponds were clearly overpopulated. In pond 4 , the owner complained that dissolved oxygen concentrations were extremely low (Table 2), imparing fish growth. In situ measurements carried out early in the morning, showed values as low as $0.65 \mathrm{mg}$ $\mathrm{L}^{-1}$. Thus, the larger TOC concentrations observed may be due to

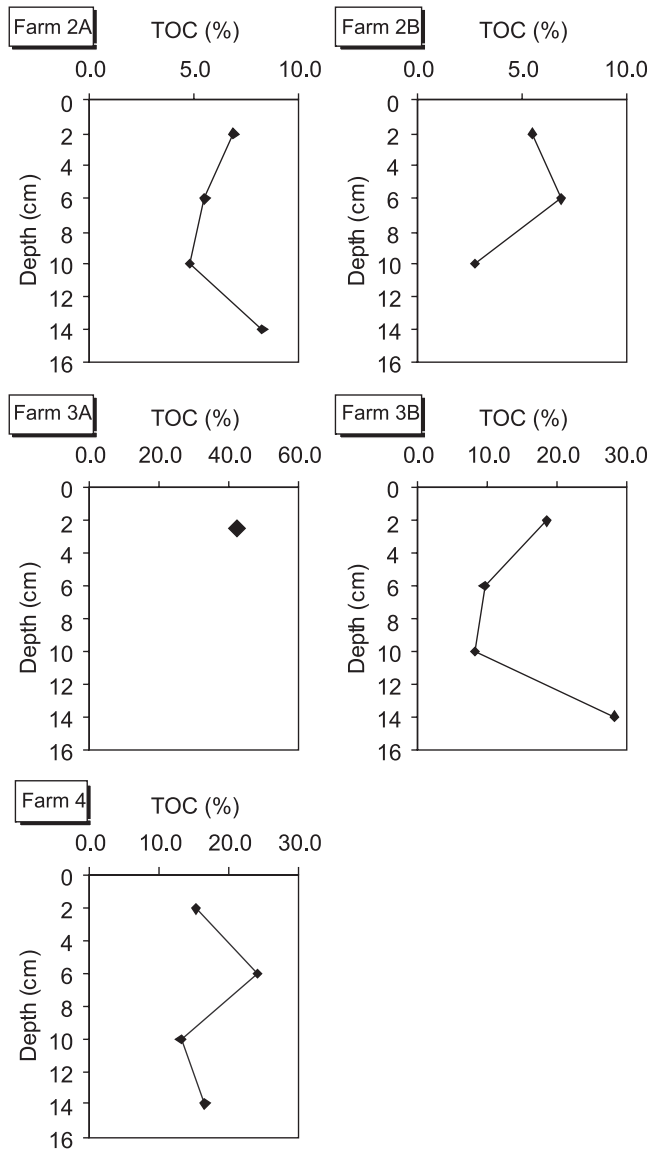

Figure 2. Total organic carbon (TOC) in sediment profiles of the studied fish ponds organic matter preservation associated with the reported low dissolved oxygen concentration.

Considering this intensive modification of the sediment characteristics associated to the present activity, it would not be surprising that the influence of previous gold mining activity would be now unnoticeable. Nevertheless, one of the farm ponds that registered past gold mining activity presented the highest $\mathrm{Hg}$ concentrations in sediments (up to $300 \mathrm{ng} \mathrm{g}^{-1}$, Figure 3). The other sampling sites presented values below $100 \mathrm{ng} \mathrm{g}^{-1}$, usually found at uncontaminated or only slightly contaminated areas (background concentrations are not available for this region). Ponds in farm 2 and pond $3 \mathrm{~A}$, flooded in areas also subjected to past gold mining activity did not present abnormal concentrations. Thus, the increased $\mathrm{Hg}$ concentrations observed in pond $3 \mathrm{~B}$ can not be unequivocally associated to gold mining. Other geochemical factors such as complexation with organic matter should also be responsible for the observed enrichment. Although comparison with other works in the Amazonian environment is meaningless, due to the variability of conditions, the present results were quite similar to those observed by Lechler et al. $^{23}$, who also observed a variation in the Madeira River sediments between 100 and $300 \mathrm{ng} \mathrm{g}^{-1}$. On the other hand, Gonçalves et al..$^{24}$ observed considerably higher concentrations (up to $2 \mathrm{mg} \mathrm{kg}^{-1}$ ) in the Vila Nova River (State of Acre), where gold mining was more intense.

The mercury concentrations in fishes from the investigated ponds, as shown in Table 3 are within the range observed in the literature ${ }^{3,25}$. The concentrations of this metal seem to be rather
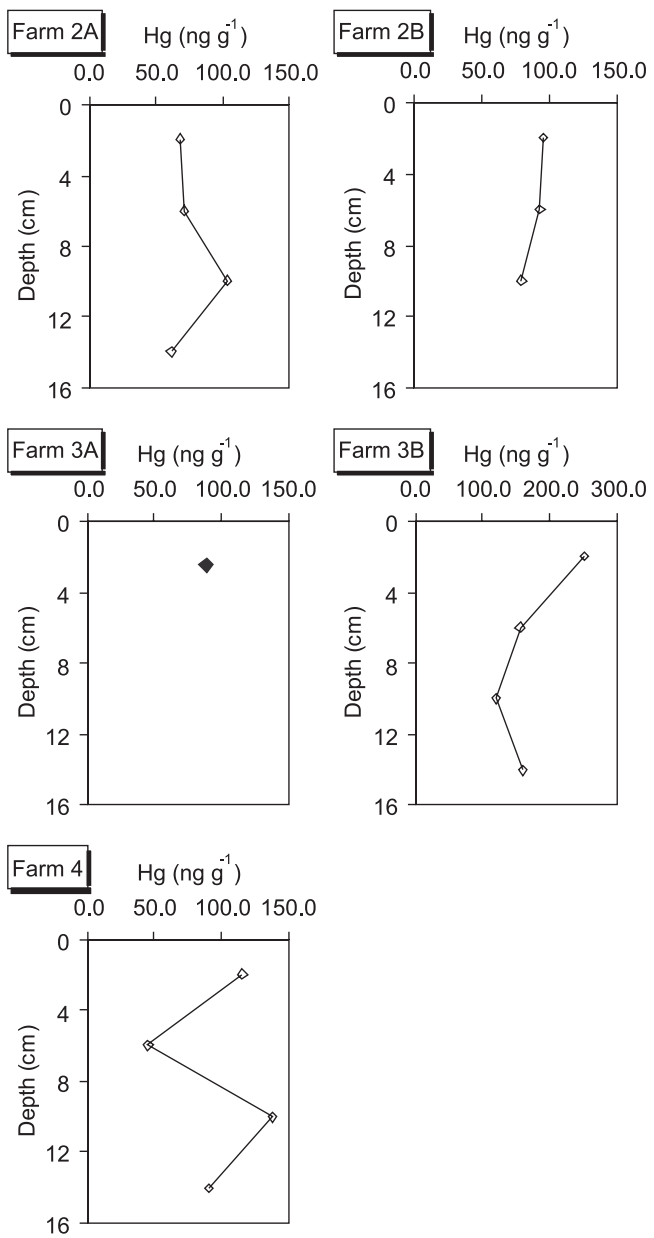

Figure 3. Total mercury concentrations in the sediment profiles of the studied fish ponds 
controlled by trophic factors. The carnivorous fishes Trairão, Traira and Tucunaré presented the highest concentrations no matter the location. Although its highest mercury concentration in sediments, farm 3 fishes do not seem to be biomagnifying this contaminant from the environment. Actually, the low environmental transfer rates observed were expected since grown fishes are fed with ration that probably does not contain large amounts of mercury. The very high mercury concentrations observed in the Trairão are probably associated with the large size of the animals and its high position in the trophic chain.

\section{Soils}

From the TOC soil profiles displayed in Figure 4, it can be drawn that organic matter is frequently enriched at the surface horizons. This should indicate a persistent and intensive source of organic matter for the soil surface (leaves and roots), but can also point out to a fast degradation within deeper layers in the soil. It could be observed in loco that the soils did not present any O horizon, indicating that leaching in the region must be significant, affecting mercury accumulation in the soils. Some authors established that mercury should accumulate in the B horizon, associated with iron oxides $^{9}$. The results presented in Figure 5 do not confirm this behavior (only profile WPS6 presents a noticeable enrichment at
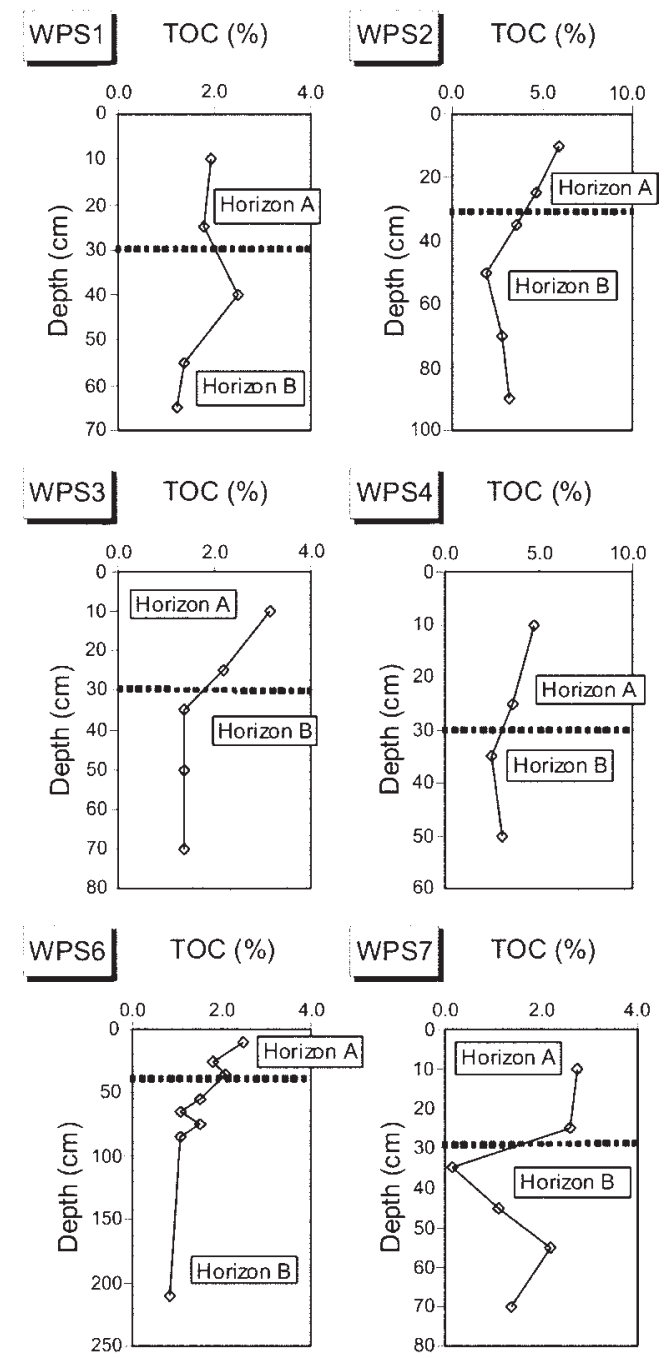

Figure 4. Total organic carbon (TOC) concentrations in soil profiles of the studied area the B horizon), probably due to the leaching effect. On the other hand, mercury seems not to be controlled by TOC concentrations as demonstrated by the observed low correlation coefficient between these two variables $(r=-0.20 ; p<0,05)$.

The $\mathrm{Hg}$ concentrations observed in the present work are considerably lower than those observed by Roulet et al. ${ }^{9}$, Lechler et al. ${ }^{23}$ and Fadini et al. ${ }^{11}$, who considered concentrations up to 300 $\mathrm{ng} \mathrm{g}^{-1}$ as natural for the region. On the other hand Lacerda et al. ${ }^{26}$ measured mercury concentrations in 30 superficial soil samples in Alta Floresta region and found concentrations ranging from 15 to $275 \mathrm{ng} \mathrm{g}^{-1}$, associating variations to present and previous gold mining atmospheric inputs. Even though Lacerda et al. ${ }^{26}$ did not checked for the type of soil they were working on, neither for the mercury distribution within the soil column, it seems clear that their results indicate that the Alta Floresta soils top layers have low background values. Since in the work of Lacerda et al. ${ }^{26}$ deeper soil profiles were not studied, they could not state that there was leaching in A horizon and accumulation in B horizon, as the above authors observed. Nevertheless, in the present work, the absence of soil enrichment in Alta Floresta soil profiles is confirmed by the results presented in Figure 5.

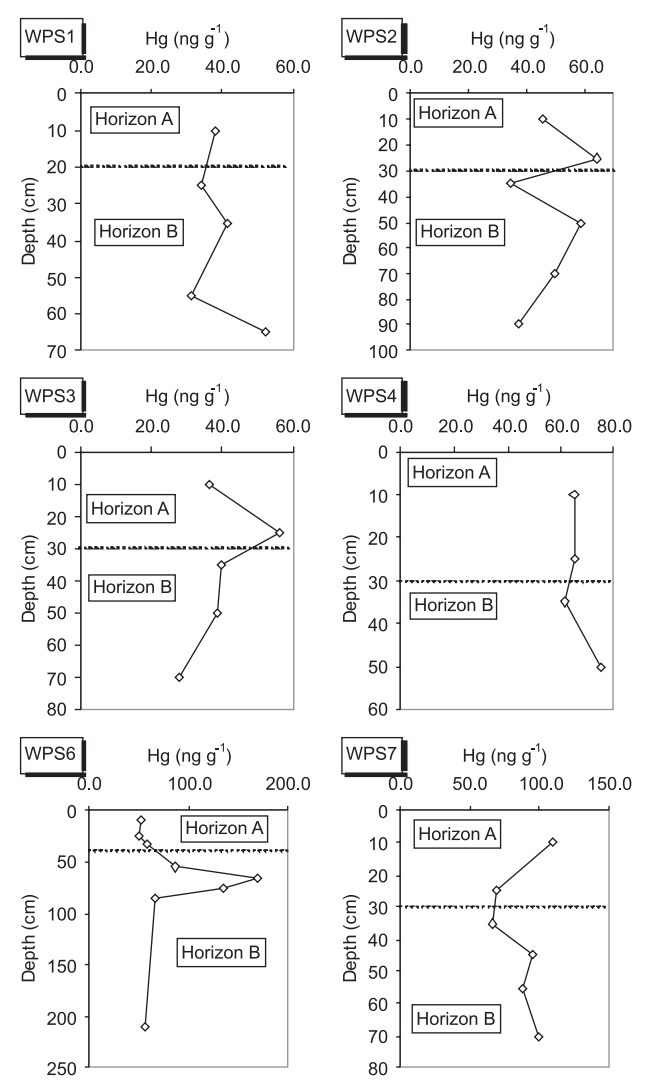

Figure 5. Total mercury concentrations in soil profiles of the studied area

\section{CONCLUSIONS}

The fish ponds sediments in the studied area tend to have their chemical characteristics controlled rather by the management procedures (liming for instance) than by the historic utilization of the pond or neighboring soil characteristics. Mercury concentrations, respond to these management procedures. It is nonetheless possible that when the loads of mercury are exceedingly high, this contamination can also be observed in the sediment. Although the slight increase in concentrations observed in pond $3 \mathrm{~B}$ should be an 
example, further studies must be carried out to confirm this behavior. It is interesting to note that liming was considered as a methylation suppressor $^{27}$ and therefore, a significant reduction in trophic chain biomagnification should be expected in intensively limed fish ponds. Furthermore, grown fishes are fed with ration, therefore absorbing very little mercury from the environment. Thus, fish concentrations in the ponds did not respond to environmental levels, but seem to be controlled by the trophic characteristics.

The distribution of $\mathrm{Hg}$ in the soil profiles did not confirm any leaching process leading to the subsequent enrichment of the B horizon. On the other hand, association of mercury with the A horizon organic matter could not be identified, showing that both of these geochemical agents do not control mercury concentrations within the soil profiles. Soils presented lower concentrations when compared to the results obtained by other authors in the Amazonian environment. The soil $\mathrm{Hg}$ contents found in the present work do not support any evidence of a natural mercury geological enrichment of Amazonian soils. Thus, it can be stated that the larger concentrations reported in the literature may not be widespread throughout the Amazonian environment and a screening program for mercury concentrations in soils is still necessary before any generalization.

\section{ACKNOWLEDGEMENTS}

The authors are thankful for the Brazilian Ministry of Health (VIGISUS programme) which provided financial support for this work. It is also necessary to thank all the fish farmers for allowing sampling and for their support in the field procedures.

\section{REFERENCES}

1. Wasserman, J. C.; Hacon, S.; Wasserman, M. A.; Ambio 2003, 32, 336.

2. Instituto Brasileiro de Geografia e Estatística; IBGE - Centro de Documentação e Disseminação de Informações: Rio de Janeiro, 2000, pp CD.

3. Hacon, S.; Farias, R. A.; Campos, R. C.; Argento, R. R.; Caires, S. M.; Rossi, A. P.; Valente, J.; Tobar, S.; Wasserman, J. C.; Environ. Sci. 2003, 10, 121.
4. Hacon, S.; Farias, R. A.; Argento, R. R.; Campos, R. C.; Rossi, A. P.; Wasserman, J. C.; J. Phys. IV 2003, 107, 357.

5. Mallas, J.; Benedito, N.; Ambio 1986, 15, 248.

6. Cleary, D.; Thornton, I.; Brown, N.; Karantzis, G.; Delves, T.; Worthington, S.; Nature 1994, 369, 613.

7. Lacerda, L. D.; Nature 1995, 374, 20.

8. Nriagu, J. O.; Proceedings of the International Symposium on Environmental Geoqchemistry in the Tropical Countries, Niterói, Brasil, 1993.

9. Roulet, M.; Lucotte, M.; Saint-Aubin, A.; Tran, S.; Rheault, I.; Farella, N.; Da Silva, E. D.; Dezencourt, J.; Passos, C. J. S.; Soares, G. S.; Guimaraes, J. R. D.; Mergler, D.; Amorim, M.; Sci. Total Environ. 1998, 223, 1.

10. Roulet, M.; Lucotte, M.; Rheault, I.; Tran, S.; Farella, N.; Canuel, R.; Mergler, D.; Amorim, M.; IV International Conference on the Geochemistry of the Earth's Surface, Ilkley, Yorkshire, England, 1996.

11. Fadini, P. S.; Jardim, W. F.; Sci. Total Environ. 2001, 275, 71.

12. Valle, C. M.; Santana, G.; Augusti, R.; Egreja-Filho, F. B.; C.Windmöller, C.; Chemosphere 2005, 58, 779 .

13. Aula, I.; Braunschweiler, H.; Leino, T.; Malin, I.; Porvari, P.; Hatanaka, T; Lodenius, M.; Juras, A. In Mercury Pollution: Integration and Synthesis; Watras, C. J.; Huckabee, J. W., eds.; Lewis Publishers: Boca Raton, 1994, p. 21.

14. Bidone, E. D.; Castilhos, Z. C.; Cid de Souza, T. M.; Lacerda, L. D.; B. Environ. Contam. Toxicol. 1997, 59, 194.

15. Roulet, M.; Lucotte, M.; Water, Air, Soil Pollut. 1995, 80, 1079.

16. Barbosa, R. C. M.; Neves, A. D. S.; Comissão Executiva do Plano da Lavoura Cacaueira, Ministério da Agricultura: Belém, Pará, 1985, p. 30.

17. Amouroux, D.; Wasserman, J. C.; Tessier, E.; Donard, O. F. X.; Environ. Sci. Technol. 1999, 33, 3044.

18. Strickland, J. D. H.; Parsons, T. R.; A Practical Handbook of Seawater Analysis, Fisheries Research Board of Canada: Ottawa, 1972.

19. Martinotti, W.; Camusso, M.; Guzzi, L.; Patrolecco, L.; Pettine, M.; Water, Air, Soil Pollut. 1997, 99, 325.

20. Relexans, J.; Lin, R.; Castel, J.; Etcheber, H.; Laborde, P.; Oceanologica Acta 1992, 15,639 .

21. Malm, O.; Pfeiffer, W. C.; Bastos, W. R.; Souza, C. M. M.; Ci. Cult. J. Braz Ass. Adv. Sci 1989, 41, 88.

22. Campos, R. C.; Curtius, A. J.; Seminario Nacional de Riscos e Consequências do Uso do Mercúrio, Brasília, Brasil, 1990.

23. Lechler, P. J.; Miller, J. R.; Lacerda, L. D.; Vinson, D.; Bozongo, J.-C.; Lyons, W. B.; Warwick, J. J.; Sci. Total Environ. 2000, 260, 87.

24. Goncalves, C.; Favaro, D. I. T.; Melfi, A. J.; de Oliveira, S. M. B.; Vasconcellos, M. B. A.; Fostier, A. H.; Guimaraes, J. R. D.; Boulet, R.; Forti, M. C.; J. Radioanal. Nucl. Chem. 2000, 243, 789.

25. Malm, O.; Environ. Res. 1998, 77-section A, 73

26. Lacerda, L. D.; de Souza, M.; Ribeiro, M. G.; Environ. Pollut. 2004, 129, 247.

27. Melamed, R.; Villas-Boas, R. C.; Sci. Total Environ. 2000, 261, 203. 